\title{
Preferiría no firmar... \\ Sobre algunos problemas políticos en la filosofia de Giorgio Agamben
}

\author{
I would prefer not to sign... \\ On some Political Problems in Agamben's \\ Philosophy
}

\author{
GERMÁN OSVALDO PRÓSPERI \\ Universidad Nacional de La Plata, Argentina
}

Recibido: 27/06/2018 Aceptado:13/09/2018

\begin{abstract}
RESUMEN
En Homo sacer I. Il potere sovrano e la nuda vita, Giorgio Agamben recuerda una expresión que le dirigiera Walter Benjamin a Pierre Klossowski e, indirectamente, al grupo Acéphale: vous travaillez pour le fascisme. En este artículo quisiéramos mostrar que es el pensamiento político-ontológico del propio Agamben, y también en cierto sentido el de Benjamin - quien ha influido de modo decisivo en el filósofo italiano -, el que en verdad corre el riesgo de trabajar para el fascismo. Mostraremos por eso la necesidad de distinguir dos niveles de lo político: un nivel trascendental y un nivel empírico. Si no se atiende a esta distinción, argumentaremos, se corre el riesgo de trabajar, efectivamente, para el fascismo.
\end{abstract}

PALABRAS CLAVE

POLÍTICA, DERECHO, VIOLENCIA, FASCISMO, PODER

ABSTRACT
In Homo sacer I. Il potere sovrano e la nuda vita, Giorgio Agamben brings back a phrase
Walter Benjamin addressed to Pierre Klossowski and, indirectly, to the group Acéphale: vous
travaillez pour le fascisme. In this article we aim at demonstrating that it is Agamben's political-

(C) Contrastes. Revista Internacional de Filosofía, vol. XXIV-Nº1 (2019), pp. 105-121. ISSN: 1136-4076

Departamento de Filosofía, Universidad de Málaga, Facultad de Filosofía y Letras Campus de Teatinos, E-29071 Málaga (España) 
ontological thinking and, to some extent, Benjamin's views -a crucial influence over the Italian philosopher- which may work for fascism. We will therefore prove the need to differentiate two levels of politics, namely the transcendental and the empirical. Unless we are aware of this difference, we may indeed be working for fascism.

KEYWORDS

POLITICS, LAW, VIOLENCE, FASCISM, POWER

\section{INTRODUCCIÓN}

HaCia El FINAL DE LA SEGUNDa parte de Homo sacer I. Il potere sovrano e la nuda vita, Giorgio Agamben recuerda un testimonio de Pierre Klossowski según el cual Walter Benjamin le habría expresado sus reservas respecto a las actividades del grupo Acéphale con la expresión: vous travaillez pour le fascisme (cf. 1995, p. 125). ${ }^{1}$ La crítica de Benjamin iba dirigida sobre todo a las investigaciones llevadas adelante por Georges Bataille, criticado también, en varios textos, por el propio Agamben. ${ }^{2}$ Ahora bien, en este artículo quisiéramos mostrar que, lejos de lo que podría pensarse a primera vista, es el pensamiento político-ontológico del propio Agamben, y también en cierto sentido el de Benjamin -quien ha influido de modo decisivo en el filósofo italiano-, el que corre el riesgo de trabajar para el fascismo. Para demostrar esto, procederemos en tres momentos. En el primero, consideraremos la lógica que estructura la filosofía política de Agamben, centrada en la categoría de «desactivación»o «suspensión». En el segundo, consideraremos las consecuencias que acarrea, o puede llegar a acarrear, la aplicación de esta lógica a situaciones políticas concretas. Por último, mostraremos la necesidad de distinguir dos niveles de lo político o, por lo pronto, de su abordaje filosófico: un nivel trascendental y un nivel empírico. Si no se atiende a esta distinción, argumentaremos, se corre muchas veces el riesgo de trabajar, efectivamente, para el fascismo.

\section{LA DESACTIVACIÓN DE LA MÁQUINA}

En Il Regno e la Gloria, Agamben muestra que el poder en Occidente, al menos desde los primeros siglos del cristianismo en adelante, se ha construido

1 El mismo episodio es narrado por Agamben en el ensayo «Bataille e il paradosso della sovranità» (1996, pp. 87-95).

2 Para una crítica a la noción batailleana de soberanía, $c f$. AGAMBEN, 1996, pp. 87-95; para una crítica a la noción de sagrado y de sacrificio, $c f$. AGAMBEN, 1995, pp. 124-127; para una crítica a la noción de negatividad, $c f$. AGAMBEN, 1982, pp. 64-67; por último, para una contraposición entre Bataille y Kojève, $c f$. AGAMBEN, 2002, pp. 12-20. 
a partir de una bipolaridad esencial: por un lado, el paradigma soberano, trascendente, fundado en la idea del Dios-Padre que reina pero no gobierna; por el otro, el paradigma económico, inmanente, fundado en la idea del DiosHijo que gobierna pero no reina. Por tal motivo, la máquina gubernamental es necesariamente bipolar. ${ }^{3}$ En el capítulo «Archeologia della Gloria», por ejemplo, Agamben sostiene que «theologia y oikonomia constituyen [...] una máquina bipolar, de cuya distinción y de cuya correlación resulta el gobierno divino del mundo» (2007, p. 253). El polo soberano habría dado lugar a la formación del Estado moderno y el polo económico habría dado lugar a la administración biopolítica de las sociedades contemporáneas. Una de las tesis que desarrolla Agamben en este texto, rectificando en parte los análisis de Michel Foucault, ${ }^{4}$ consiste en mostrar que el poder occidental, a partir de la teología cristiana de los primeros siglos, es siempre soberano-gubernamental, es decir político-económico. Esta estructura bipolar es característica de todas las máquinas agambenianas. A ella habría que agregar, además, la idea del centro vacío. Ya desde el inicio de Il Regno e la Gloria, Agamben vuelve explícito el otro aspecto decisivo de la máquina: «el centro de la máquina gubernamental está vacío. El trono vacío [...] es, en este sentido, el símbolo más apremiante del poder» $(2007$, p. 11). El vacío central alude a una filosofía no esencialista: el poder no posee una esencia o una substancia, es «originariamente» an-árquico.

Esta misma estructura (dos polos y un centro vacío) se repite por ejemplo en la máquina productora de lo humano. ${ }^{5}$ En L'aperto. L'uomo e l'animale, Agamben sostiene que la máquina antropológica es el dispositivo que articula y conjuga «un elemento natural (o animal) y un elemento sobrenatural, social o divino» (cf. 2002, p. 24). Estos dos elementos constituyen los dos polos de la máquina. En su centro, además, continúa Agamben, se genera una zona de indistinción «que está, en verdad, perfectamente vacía» (cf. 2002, p. 43). El centro vacío de la máquina indica que el hombre no posee una esencia propia

3 Sobre el concepto de máquina gubernamental en Agamben, $c f$. WATKIN, 2014, pp. 209-243.

4 Nos referimos a las tesis avanzadas en el último capítulo de La volonté de savoir y desarrolladas en los cursos de fines de los años setenta en el Collège de France. En efecto, en el último capítulo del primer tomo de la Histoire de la sexualité, Foucault avanza la tesis de que alrededor de los siglos XVII-XVIII el poder soberano, fundado en el derecho de matar o de dejar vivir, sufre una «profunda transformación» ( $c f$. FOUCAULT, 1976, p. 179) y se configura, de allí en adelante, como un biopoder, es decir, como «un poder que se ejerce positivamente sobre la vida, que procura administrarla, aumentarla, multiplicarla, ejercer sobre ella controles precisos y regulaciones generales» (1976, p. 180).

5 Sobre el concepto de máquina antropológica en Agamben, $c f$. CALARCO, 2008, pp. 88-102. 
ni una naturaleza que lo defina: «La máquina antropológica del humanismo es un dispositivo irónico, que verifica la ausencia para Homo de una naturaleza propia, manteniéndolo suspendido entre una naturaleza celeste y una terrena, entre lo animal y lo humano» (2002, p. 35). El hombre no responde entonces a una esencia, sino que es el producto o el efecto, necesariamente político, de la articulación y desarticulación, de las conexiones y desconexiones, que efectúa la máquina antropológica. Por eso Agamben sostiene que el funcionamiento de la máquina designa una «operación metafísico-política fundamental, en la cual solamente algo como un 'hombre' puede ser decidido y producido» (2002, p. 28).

Ahora bien, la estrategia política -aunque el término «estrategia» ya no resulta adecuado -6 propuesta por Agamben frente al funcionamiento de la máquina gubernamental, y frente a las diversas máquinas examinadas a lo largo de su obra (antropológica, lingüística, sacrificial, etc.), consiste en «desactivar» su funcionamiento. La desactivación supone una suspensión de la polaridad. Por eso no se trata para Agamben, como no se cansa de reiterárnoslo en diversos textos, de contraponer un polo de la máquina al otro, es decir de hacer jugar la dinámica antagónica, sino de suspender la oscilación, detener el movimiento de la máquina a fin de que pueda exhibirse su vacío central. Mencionamos dos pasajes, que podrían sin duda multiplicarse, para mostrar esta lógica de la desactivación. El primero pertenece al texto L'uso dei corpi; el segundo, a L'aperto:

No se trata, de hecho, de pensar, como se ha hecho hasta ahora, nuevas y más eficaces articulaciones de los dos elementos, jugando una contra la otra las dos mitades de la máquina. Ni tampoco se trata de remontarse arqueológicamente a un inicio más originario: la arqueología filosófica no remite a otro inicio más que a aquel que puede, eventualmente, resultar de la desactivación de la máquina (en este sentido la filosofía primera es siempre filosofía última) (2014, p. 336).

En nuestra cultura el hombre -lo hemos visto- ha sido siempre el resultado de una división, y, a la vez de una articulación del animal y de lo humano, en el cual uno de los dos términos de la operación era también la puesta en juego. Volver inoperosa la máquina que gobierna nuestra concepción del hombre significará por lo tanto no ya buscar nuevas -más eficaces o más auténticas- articulaciones,

6 Agamben critica la noción foucaultiana de «estrategia» en L'uso dei corpi (2014, pp. 133-148). En efecto, según Agamben, Foucault no habría sido capaz de pensar «una forma de vida que no asuma nunca la figura de un sujeto libre; es decir [...] de una zona de la ética del todo sustraída a las relaciones estratégicas, de un Ingobernable que se sitúa más allá tanto de los estados de dominio cuanto de las relaciones de poder» (2014, p. 148). 
cuanto exhibir el vacío central, el hiato que separa -en el hombre- el hombre y el animal, arriesgarse en este vacío: suspensión de la suspensión, shabbat tanto del animal cuanto del hombre (2002, p. 94).

Como queda claro en estos pasajes, no se trata para Agamben de reproducir la polaridad constitutiva de la máquina, sino de desactivar su funcionamiento, es decir de neutralizar ambos polos con el objetivo de hacer emerger el hiato que la máquina custodia en su centro (en el caso de la máquina gubernamental, el centro designa la inoperosidad, la an-arquía cuyo símbolo es el trono vacío; en el caso de la máquina antropológica, la ausencia de naturaleza o esencia humana). La noción de comunidad, en este sentido, designa para Agamben este espacio vacío, ajeno a toda propiedad y pertenencia a cualquiera de los dos polos. Es evidente que, desde esta perspectiva que se inscribe en la línea de la filosofía de lo común propuesta por Jean-Luc Nancy (2004) y Maurice Blanchot (1983), retomada luego por Roberto Esposito (2006) entre otros, lo común no puede asentarse en ningún tipo de identidad, sino más bien en su revocación, en el compartir el mero ser-así de las singularidades cualesquiera (cf. AGAMBEN, 1990). Esta política de la comunidad (cualquiera), por lo tanto, no puede remitir a ninguno de los dos polos de la máquina gubernamental: hacerlo implicaría correr el riesgo, para utilizar las palabras de Benjamin, de trabajar para el fascismo.

\section{PREFERIRÍA NO FIRMAR...}

Para demostrar las consecuencias peligrosas que puede acarrear esta política de la desactivación -que bien podría designarse como una política de lo neutro (en su sentido etimológico: ne...uter, ni-ni, es decir ni un polo ni el otro)- quisiéramos mencionar un breve escrito de Agamben, publicado el 18 de octubre de 2017 en la página web de la editorial Quodlibet, titulado «Perché non ho firmato l'appello sullo ius soli». ${ }^{7}$

No es nuestra intención utilizar una suerte de argumentum ad hominem. El objetivo de esta sección es mostrar, más bien, los riesgos que se corren - o pueden correrse- cuando se aplica sin ciertas cautelas esta lógica de la desactivación, explicada en el apartado previo, a situaciones concretas. Lo interesante, por eso mismo, no es la singularidad que en este caso lleva por apellido «Agamben»-pensador que nos parece desde todo punto de vista fundamental y al cual expresamos nuestra más sincera admiración-, sino los presupuestos filosóficos implícitos en su justificación.

7 Puede consultarse el texto de Agamben en el siguiente link:

https://www.quodlibet.it/giorgio-agamben-perch-on-ho-firmato-l-appello-sullo-ius-soli [Consultado el 17 jun. 2018]. 
En este breve escrito, Agamben se dedica a explicar por qué, a pesar de figurar como firmante de un petitorio en el que se reclamaba el derecho a la ciudadanía para los inmigrantes, él no había firmado ni estaba dispuesto a hacerlo. Luego de reconocer la alarmante situación de los inmigrantes, Agamben explica «las razones de su rechazo» ${ }^{8}$ aduciendo que, lejos de tratarse de una indiferencia respecto a los inmigrantes, su cuestionamiento concierne «a la idea misma de ciudadanía». Esta idea supone que un individuo se encuentre sometido «a las leyes y al sistema político de un Estado que no ha elegido y del cual ya no puede desvincularse». El motivo de su rechazo, entonces, perfectamente consecuente $-\mathrm{y}$ este es el punto importante- con sus postulados teórico-filosóficos nucleados en la noción de «desactivación» o de «volver inoperante», radica en que la idea de ciudadanía remite a uno de los dos polos de la máquina gubernamental:

Estos Estados se llaman también Estados-Nación porque hacen del nacimiento el principio de la inscripción de los seres humanos en su interior. No importa cuál sea el criterio procedimental de esta inscripción, el nacimiento de padres ya ciudadanos (ius sanguinis) o el lugar de nacimiento (ius soli). El resultado es en todo caso el mismo: un ser humano se encuentra necesariamente sujeto a un orden jurídico-político...

La argumentación de Agamben podría resumirse de la siguiente manera: no he firmado el petitorio en el que se reclamaba la otorgación del derecho de ciudadanía a los inmigrantes porque no estoy de acuerdo con la idea misma de ciudadanía en la medida en que se funda en la lógica soberana del Estado nacional. Firmar el petitorio significaría entonces, para Agamben, según las palabras de Benjamin, trabajar para el fascismo, puesto que se estaría legitimando implícitamente, al reconocer la necesidad del ius soli, el polo soberano de la máquina gubernamental y por eso mismo la lógica antagónica de su funcionamiento. ${ }^{9}$ Por eso creemos que, lejos de ser una mera reticencia

8 Todas las citas de este texto han sido extraídas de la página web cuya dirección consignamos en la nota previa.

9 Creemos que el análisis de Agamben, al no ver el carácter anfibológico del Estado, resulta insuficiente. El Estado puede ser totalitario o dictatorial, pero también puede ser emancipador y libertario. Si se descuida este doble aspecto del Estado se corre el riesgo de olvidar que, muchas veces, sobre todo en nuestras sociedades periféricas, lo que nos espera en general fuera del Estado son las lógicas (financieras) de un modelo económico neoliberal. Nadie lo ha expresado mejor que Eduardo Rinesi: «Es verdad que el Estado sirve [...] para garantizar el dominio de unas clases de hombres sobre otras [...]. Pero ya hemos dicho que el hecho de que las cosas sean así no debe llevarnos a imaginar, ingenuamente, que es fuera y lejos del Estado, o contra él, que habremos de alcanzar la libertad, la autonomía o la realización. De hecho, en la Argentina y en otros países de nuestra región hemos aprendido amargamente que lo que con más 
o indecisión, como el mismo Agamben pareciera por un momento -sólo por un momento- dejar entrever («Me doy perfectamente cuenta que la condición de apátrida y de migrante es un problema que no puede ser evitado, pero no estoy seguro de que la ciudadanía sea la mejor solución»), se trata de una consecuencia directa, y absolutamente coherente, con sus postulados filosófico-políticos. En efecto, en la medida en que, como vimos, no se trata de hacer jugar un polo contra el otro, es decir de buscar nuevas articulaciones que reproduzcan el funcionamiento antagónico de la máquina gubernamental, Agamben se ve «obligado», a fin de no caer en una contradicción con su propio pensamiento, a no firmar el petitorio. No sería coherente postular la desactivación del funcionamiento bipolar de la máquina y al mismo tiempo firmar un petitorio en el que se recurre a un dispositivo inherente a uno de sus polos, en este caso el soberano.

Hemos dicho que no se trata de aplicar aquí una suerte de argumentum ad hominem. Poco importa la singularidad-Agamben para lo que queremos mostrar en este artículo, lo que sí importa es su filosofía política y la relación de coherencia $-\mathrm{y}$, por qué no, de «coacción» lógica- entre su pensamiento y su decisión de no firmar el documento. Ahora bien, lo que debe despertar nuestras sospechas y obligarnos a reflexionar es que los efectos concretos de la decisión de Agamben coinciden exactamente con los de un fascista o un partidario de la Liga Nord. Al igual que Agamben, aunque por razones claramente diversas, incluso opuestas, este hipotético reaccionario tampoco habría firmado el petitorio. En el caso de Agamben, su decisión de no firmar se basa en el rechazo de la idea misma de ciudadanía y del ius soli; en el caso del fascista, en que no está de acuerdo en conferirle el derecho de ciudadanía, al que sí adhiere, a los inmigrantes, a los que desprecia. Las razones, como puede observarse, son radicalmente diversas; sin embargo, en sus efectos concretos coinciden, y coinciden perfectamente. ${ }^{10}$

seguridad nos espera fuera y lejos del Estado es la inclemencia de un mundo salvaje y despiadado gobernado por las puras leyes del mercado» (2015, p. 113). La misma observación formula Ernesto Laclau, esta vez dirigida directamente a Agamben: «La soberanía, finalmente, puede ser totalitaria en el caso extremo en que implica una concentración total del poder; pero también, profundamente democrática, si implica un poder articulador y no determinante, esto es, cuando 'otorga poder' a los desvalidos. En ese caso, como ya hemos señalado, la soberanía debería concebirse como hegemonía» (2008, p. 121).

10 Desde una perspectiva pragmatista, que sin embargo no desarrollaremos aquí, la posición de Agamben es en efecto perfectamente idéntica a la de un fascista. En tanto el pragmatismo (al menos el de William James, por mencionar un nombre célebre) considera las posiciones teóricas, en la línea de Pierce, en función de sus efectos concretos, en este caso no firmar el petitorio, ambas posiciones, la de derecha y la de Agamben, coinciden. En el famoso Pragmatism: A New Name for Some Old Ways of Thinking, James sostiene que el método pragmatista consiste en 
Dijimos en la introducción que una de las referencias indudables de Agamben es el pensamiento de Benjamin. ${ }^{11}$ Quisiéramos sugerir que este problema que estamos intentando mostrar aquí hunde sus raíces justamente en la filosofía de Benjamin, al menos en algunas de sus tesis. Consideremos un ejemplo.

En el inagotable ensayo «Zur Kritik der Gewalt», ${ }^{12}$ Benjamin avanza la tesis de que el dispositivo jurídico es inherentemente violento. No es nuestra intención desarrollar aquí el denso y profundo análisis de este ensayo benjaminiano, sino simplemente mostrar algunos puntos que tienen una relación directa, creemos, con el pensamiento filosófico-político de Agamben. En principio, Benjamin distingue entre la violencia propia del aparato jurídico a la que llama «violencia mítica [mythische Gewalt]» (cf. BENJAMIN, 1999, p. 197) y que supone una oscilación bipolar entre una fuerza que instituye la ley y una que la preserva, y una violencia externa a dicha polaridad a la que denomina «violencia divina [göttliche Gewalt]» (cf. ibid.). Mientras que la violencia mítica estaría representada, en el ensayo de 1921, por la «huelga general política [politische Generalstreik]» (cf.ibid., pp. 193-195), funcional por eso mismo al estado de cosas y al sistema legal del Estado, la «huelga general proletaria [proletarischen Generalstreik]» (ibid.), decididamente revolucionaria, supondría una forma de violencia que, en razón de su prescindencia de todo fin, es decir en razón de ser un medio puro [reinen Mittel] o un medio sin fin-y nótese la importancia que posee este concepto en

«tratar de interpretar cada noción en función de sus consecuencias prácticas respectivas. ¿Cuál sería la diferencia práctica si esta noción fuese verdadera en lugar de aquella otra? Si no puede establecerse ninguna diferencia práctica, entonces las alternativas se reducen a lo mismo») (1922, p. 45). Resulta evidente que, desde esta perspectiva, tanto la posición de Agamben cuanto la de un fascista, en la medida en que en ningún caso se firma la solicitud y por ende sus efectos prácticos coinciden, son idénticas.

11 Sobre el pensamiento político de Benjamin, $c f$. MARTEL, 2012; STEINER, 2010, pp. 50-79; FENVES, 2010, pp. 187-226. Sobre la relación entre Benjamin y Agamben desde una perspectiva política, $c f$. MORAN y SALZANI, 2015; DE LA DURANTAYE, 2009, pp. 43-54. Para una crítica a la lectura que Agamben realiza de Benjamin, $c f$. DIDI-HUBERMAN, 2012, pp. 51-124.

12 Para una contextualización histórica y biográfica de este ensayo, $c f$. MÜLLER, 2003, pp. 468-471; PROCYSHYN, 2014, pp. 390-391; KAMBAS, 1984, pp. 71-89. Sobre las diversas lecturas a las que ha dado lugar el ensayo de Benjamin, $c f$. KELLOGG, 2011, pp. 71-90. 
el pensamiento de Agamben ( $c f$. AGAMBEN, 1996)-, resulta destructora del orden jurídico imperante y absolutamente inasimilable por la forma-Estado. ${ }^{13}$ Nadie lo ha explicado mejor que Werner Hamacher:

Mientras la huelga general política está centrada sólo en un cambio de las relaciones de dominio y así en la conservación y fortalecimiento de la violencia del Estado, la huelga general proletaria no apunta a otra cosa que a la destrucción del aparato del estado y del orden jurídico conservado por él (2013, p. 195).

Por eso la posición de Benjamin, más allá de sus críticas a un «anarquismo infantil», ha sido justamente identificada con un cierto anarquismo, mote que también ha sido aplicado, a pesar de las precauciones del autor, al pensamiento de Agamben. ${ }^{14}$

13 En un capítulo decisivo de Stato di eccezione, Agamben no sólo hace referencia al ensayo de Benjamin sobre la violencia, sino que lo contrapone directamente a la teoría de la soberanía de Carl Schmitt, la cual concierne, al menos in extremis, a la idea de Estado nación. Según explica Agamben, el «objetivo del ensayo es el de asegurarse la posibilidad de una violencia [...] absolutamente 'por fuera' (außerhalb) y 'más allá' (jenseits) del derecho» (2005, p. 105), y es justamente «para neutralizar la nueva figura de una violencia pura, sustraída a la dialéctica entre poder constituyente y poder constituido, que Schmitt elabora su teoría de la soberanía» (2005, p. 107). De tal manera que, concluye Agamben, «al gesto de Schmitt, que intenta a cada paso reinscribir la violencia en un contexto jurídico, Benjamin responde buscando en cada ocasión asegurarle a ésta - como violencia pura - una existencia por fuera del derecho» (2005, p. 114). Por otro lado, en esa suerte de Adversus iure que es Karman. Breve trattato sull'azione, la colpa e il gesto, Agamben vuelve a hacer referencia al ensayo de Benjamin, en particular a su Politik der reinen Mittel ( $c f$. AGAMBEN, 2017, p. 132), esta vez para pensar, contra Kant, una praxis liberada de toda relación con un fin ( $c f$. AGAMBEN, 2017, pp. 131-136).

14 No queremos saturar el texto con referencias innecesarias, pero baste mencionar el artículo de Alexei Procyshyn en el cual podemos leer: «La huelga general [proletaria] le permite a Benjamin anclar su ideal anárquico del compromiso político en el mundo real al mostrar cómo el sujeto colectivo que manifiesta puede abandonar las relaciones institucionales y las posibilidades objetivas construyendo una situación histórica determinada y abriendo un nuevo espacio de posibilidades que de otro modo habrían permanecido inaccesibles a los agentes individuales» (2014, p. 398). Una observación similar formula Robert Sinnerbrink: «La huelga general proletaria es precisamente lo que suspende [y nótese de nuevo la importancia que posee este término en Agamben] la violencia del estado político a través de la liberación anarquista-revolucionaria del trabajo» (2014, p. 492). Mencionamos, por último, a Werner Hamacher: «Con su referencia a Marx, Benjamin logra establecer con suficiente astucia la diferencia entre la política marxista, por una parte, y la política del anarquismo, por la otra, a favor del anarquismo» (2013, p. 196; $c f$. también, y en especial, la nota al pie en pp. 196-198). Sobre el anarquismo de Benjamin, $c f$. también MARTEL, 2012, pp. 133, 143-146; BLUMENTHAL-BARBY, 2009, pp. 728-751. Por su parte, Agamben ha aludido en varias ocasiones al aspecto necesariamente anárquico del poder, aunque más no sea en el sentido etimológico del término (sin origen, sin principio, sin 
Lo que quisiéramos señalar es que, si uno se atiene al enunciado de Benjamin y considera a la vez, con el propio Benjamin, que la violencia intrínseca al derecho es repudiable pues reproduce, en tanto violencia mítica -y no divina o pura-, la bipolaridad inherente a la relación medio-fin, entonces no queda más remedio que prescindir en la medida de lo posible del derecho y del Estado que lo garantiza (función que en el ensayo «Zur Kritik der Gewalt» Benjamin le adjudica, como vimos, a la huelga general proletaria). Mencionamos este punto porque creemos que Agamben razona de la misma manera en relación al ius soli. ${ }^{15} \mathrm{El}$ derecho de ciudadanía implica una violencia inherente a la bipolaridad de la máquina gubernamental, y más en concreto una violencia propia del polo (el Estado) soberano, por lo tanto hay que prescindir del derecho de ciudadanía, incluso para los inmigrantes. Así como para Benjamin se trataba de suspender el ciclo bipolar entre la violencia que instaura la ley y la violencia que la preserva representado en la expresión «violencia mítica», asimismo se trata para Agamben de suspender el

fundamento). La política de Occidente, según Agamben, ha podido funcionar presuponiendo, como su condición de posibilidad, una radical contingencia, una anarquía. El poder es, originariamente, an-árquico, es decir in-originario: «La anarquía es lo que el gobierno debe pre-suponer y asumir sobre sí como el origen del cual proviene y, a la vez, como la meta hacia la cual se mantiene en viaje» (AGAMBEN, 2007, p. 80). Es precisamente este «origen» y esta «meta» an-árquica, presupuesta por el poder, lo que para Benjmain volvería visible la proletarischen Generalstreik. Sergei Prozorov, sin embargo, sostiene que no es justo identificar la propuesta política agambeneana con el anarquismo tout court: «De acuerdo con la lógica general de la inoperosidad, esta resolución no toma la forma ni de un relevo revolucionario ni de una destrucción anárquica del estado y del aparato legal sino que consiste más bien en la desactivación de su poder ordenador en lo que Agamben, siguiendo a Walter Benjamin, llama el 'real estado de excepción', en el cual la praxis humana es liberada de toda relación con la ley»〉 (2014, p. 7). La misma defensa de Agamben es intentada por DE LA DURANTAYE, 2009, pp. 110, 345-351. Más allá de las aclaraciones de estos autores, no sé ve muy bien cómo una praxis liberada de toda relación con la ley y el Estado no sería, en cierta manera, anárquica - cosa que el propio Benjamin reconocía, por otro lado.

15 No es casual que Agamben considere al mesianismo, uno de cuyos antecedentes es precisamente Benjamin, como una desactivación (katargēsis) de la ley: «Lo mesiánico no es la destrucción, sino la desactivación y la inobservancia de la ley» (2000, p. 93). Tampoco es casual que Werner Hamacher haya puesto en relación explícitamente las tesis del ensayo «Zur Kritik der Gewalt» con la idea de mesianismo: «Como Benjamin habla en su tratado Zur Kritik der Gewalt de una 'destitución del derecho junto a las violencias a las cuales él está sujeto como ellas a él', así puede decirse de lo mesiánico, sea del reino, sea del tiempo, que se presenta sólo en la 'destitución' o como 'destitución' de todas las instituciones epistémicas y de la voluntad» (2013, p. 100). No vale la pena destacar la importancia que tiene la noción de «destitución», íntimamente vinculada a «inoperosidad» $\mathrm{y}$ «desactivación», en la filosofía política de Agamben. Sobre este punto, $c f$. AGAMBEN, 2014, pp. 333-351. 
funcionamiento bipolar de la máquina gubernamental. Y de la misma manera que para Benjamin era preciso, para no reproducir la lógica de la violencia mítica, pensar en una violencia destituyente o deponente (la violencia divina de la huelga general proletaria), también para Agamben es necesario pensar una política que deponga la lógica del paradigma soberano-gubernamental característico de las sociedades occidentales. Por eso no sería coherente para Benjamin -más allá de las anécdotas biográficas ${ }^{16}$ apoyar la huelga general política, puesto que se estaría reproduciendo la violencia mítica del sistema jurídico, de la misma manera que no es coherente para Agamben firmar el petitorio sobre la ciudadanía de los inmigrantes, puesto que tal derecho se funda en el Estado-nación que encarna la fuerza soberana.

Podríamos construir un razonamiento similar en relación a otro problema jurídico como es por ejemplo la legalización del aborto: el dispositivo jurídico implica necesariamente una cierta violencia (puesto que para Benjamin, como vimos, la «violencia mítica» es inherente al derecho), por lo tanto no habría que apoyar a las mujeres que reclaman por su derecho a abortar ya que se estaría reproduciendo una lógica inherentemente violenta.

Nos parece que este modo de argumentación, coherente sin embargo con los presupuestos filosófico-políticos tanto de Benjamin cuanto de Agamben, esconde un riesgo inmenso: ni más ni menos que el de estar trabajando para el fascismo. ${ }^{17}$ Tanto la decisión de no firmar el petitorio acerca de la ciudadanía

16 Aclaramos esto porque no estamos queriendo decir que Benjamin no ha dado pruebas suficientes de su compromiso con las luchas políticas de su época y con toda la «tradición de los oprimidos». Nuestro objetivo, más bien, es señalar ciertos riesgos implícitos en «Zur Kritik der Gewalt» en particular, aunque se trata, creemos, de una tendencia propia del pensamiento benjaminiano que puede ser rastreada en diversos textos. Nuestro enfoque, por eso mismo, no es biográfico o personal, sino eminentemente filosófico-conceptual.

17 Este riesgo presente en el ensayo benjaminiano y, más allá, en ciertas aristas de su pensamiento en general, no le ha pasado por alto a Jacques Derrida. Las observaciones críticas que el filósofo argelino le dirige a Benjamin en su conferencia titulada «Du droit à la justice» no difieren demasiado, en ciertos puntos, de nuestra perspectiva: «Este exceso de la justicia sobre el derecho y sobre el cálculo, este desborde de lo impresentable sobre lo determinable no puede y no debe servir de excusa para ausentarse de las luchas jurídico-políticas, al interior de una institución o de un Estado, entre las instituciones o los Estados. Abandonada a sí misma, la idea incalculable y donadora de la justicia está siempre muy próxima al mal, es decir a lo peor pues puede siempre ser reapropiada por el cálculo más perverso» (1994, p. 61). El «mal» o lo «peor» de los que habla aquí Derrida se acercan a lo que nosotros llamamos, a partir de Benjamin y Agamben, trabajar para el fascismo. En nuestro caso, creemos que este riesgo detectado ya por Derrida en relación al ensayo de Benjamin se perpetúa, sin grandes cambios en su estructura esencial, en el pensamiento político de Agamben. Por eso no es intrascendente que el propio Agamben considere absolutamente errónea la lectura de Derrida. Como explica Leland De La Durantaye: «Derrida, en lo que Agamben considera una incomprensión fundamental, concibe 
para los inmigrantes cuanto la decisión, en este caso hipotética, de no apoyar la legalización del aborto, en sus efectos concretos -empíricos, diríamos-, es exactamente idéntica, desde una perspectiva pragmatista, a la decisión que tomaría un fascista o un conservador. Este punto no debe ser descuidado y es justamente el núcleo de nuestro artículo. ¿Cómo puede ser que la decisión de un filósofo de izquierda -Agamben en nuestro caso-, es más, de un filósofo para el cual la distinción derecha-izquierda carece ya de sentido, coincida, en sus efectos concretos, con la decisión de un partidario de derecha? Es una ironía muy curiosa: el autor (Benjamin) que se preguntaba si el grupo Acéphale no estaría trabajando para el fascismo era el mismo que, en el centro de su pensamiento, inoculaba, probablemente sin saberlo, una suerte de semilla acaso más peligrosa que la de sus sospechosos colegas franceses. La semilla florecería en Agamben, por supuesto. Exploraremos en lo que sigue la necesidad de tomar ciertas cautelas para que esta semilla, fundamental en el pensamiento político contemporáneo, no florezca inclinada hacia la derecha.

\section{DE LA DISTINCIÓN DE LA POLÍTICA TRASCENDENTAL Y LA EMPÍRICA}

Quisiéramos proponer una distinción al interior del pensamiento político y hablar, por un lado, de una política trascendental y, por otro, de una política empírica. Ambos términos, de más está decir, deben ser interpretados en su sentido kantiano. La política trascendental aludiría a la dimensión más profunda de lo político, a la condición de posibilidad de la política empírica. ${ }^{18}$ Esta última, por su parte, aludiría a las situaciones cotidianas, a los hechos políticos en los que nos vemos inmersos todos los días: la política mediática, los reclamos salariales, jurídicos, sindicales, etc. Creemos que los presupuestos filosófico-políticos de Agamben y de Benjamin, al menos los que hemos considerado aquí (en síntesis: la tesis de Agamben según la cual la política que viene supone la desactivación de la máquina gubernamental eminentemente antagónica y la tesis de Benjamin según la cual el dispositivo jurídico es inherentemente violento) se sitúan en la dimensión trascendental de lo político. Esto quiere decir que, independientemente de la ley que se

los argumentos de 'Para una crítica de la violencia' como figuras muy próximas a las empleadas en la Solución Final nazi»(2009, p. 109). Sobre la lectura derrideana del ensayo «Zur Kritik der Gewalt», $c f$. SINNERBRINK, 2006, pp. 485-497. Para una defensa a las críticas que identifican la posición de Agamben con una forma más o menos inerte de anarquismo, $c f$. DE LA DURANTAYE, 2009, pp. 345-351.

18 No hay que pensar que la dimensión trascendental, por ser condición de posibilidad de la dimensión empírica de la política, se encuentre en una suerte de pureza incontaminada. Como bien ha mostrado Michel Foucault en relación a su método arqueológico, el a priori es histórico, es decir las condiciones son en sí mismas condicionadas. 
reclame, del derecho por el que se luche, etc., en la medida en que se haga uso del dispositivo jurídico se estará reproduciendo una cierta violencia, puesto que la violencia (mítica) concierne al aspecto trascendental o formal, en su sentido kantiano, del aparato jurídico. Cualquier contenido material que sea filtrado por el dispositivo jurídico, cuya estructura formal es inherentemente violenta, será por eso mismo violento. No es posible pensar en un fenómeno empírico, es decir a posteriori, que no sea violento cuando la forma jurídica pura, a priori, implica necesariamente en su estructura una cierta violencia. Ahora bien, creemos que tanto Agamben como Benjamin han permanecido fieles a esta dimensión trascendental (divina o pura, en términos de Benjamin) de lo político, y han extendido sus presupuestos, sin reparos, al plano empírico. De tal manera que no han podido pensar una política más que prescindiendo del derecho (en el caso del ejemplo de Agamben, del derecho a la ciudadanía, el ius soli). Sin embargo, nos parece que a la hora de efectuar este pasaje de una dimensión trascendental de lo político a una dimensión empírica, si no se tienen en cuenta las situaciones y las complejidades propias a ese nivel empírico, se corre el riesgo de terminar coincidiendo, en sus efectos concretos, con una política fascista. Por eso estimamos que frente a las coyunturas concretas y cotidianas, sobre todo en sociedades latinoamericanas como las nuestras, muchas veces resulta aconsejable adoptar una posición al interior del antagonismo y de la polaridad y defender, por ejemplo, el estado soberano frente al mercado financiero neoliberal. Por curioso que parezca, creemos que la lógica antagónica, inherentemente violenta al igual que el dispositivo jurídico, puede resultar menos riesgosa, y en cierto sentido hasta menos violenta, que posiciones mucho más radicales como las de Benjamin o Agamben. Como dice Derrida en su ensayo sobre Lévinas: «Si la luz es el elemento de la violencia, es necesario batirse contra la luz con otra cierta luz para evitar la peor violencia, la del silencio y de la noche que precede o reprime al discurso» (1967, p. 172). Creemos que Benjamin y Agamben, al intentar pensar una política que prescinda del derecho y del Estado (de la luz, en la metáfora de Derrida) sin tener en cuenta las dos dimensiones políticas señaladas, corren el riesgo de quedar a ciegas, en la más absoluta oscuridad. ${ }^{19}$

19 En un sentido similar, aunque no idéntico, Catherine Mills ha observado al final de The Philosophy of Agamben: «En la medida en que la teoría de la liberación política de Agamben se basa a fin de cuentas en la suspensión del pasaje de la potencialidad a la acción o a la actualidad (hacer o ser), la dificultad es que su aparente radicalismo filosófico se convierta en su opuesto en el ámbito político» (2008, p. 138). 


\section{CONCLUSIÓN}

A lo largo de este artículo hemos querido mostrar que los presupuestos filosófico-políticos de Giorgio Agamben, claramente influenciado en muchos aspectos por Walter Benjamin, cuando son aplicados a situaciones concretas sin tomar ciertos recaudos pueden conducir a posiciones políticas peligrosas, muy cercanas al fascismo y la derecha. En principio, hemos explicado la estructura (dos polos y un centro vacío) de las máquinas agambenianas a fin de comprender la propuesta política del filósofo italiano. Como hemos visto, no se trata para Agamben de hacer jugar un polo contra el otro -en el caso de la máquina gubernamental el polo soberano contra el polo económico (en términos contemporáneos: el Estado nacional contra el neoliberalismo transnacional)-, sino de desactivar el funcionamiento bipolar y antagónico de la máquina. A partir de allí, hemos mostrado las consecuencias que se siguen cuando se aplica esta lógica de la desactivación a situaciones concretas como por ejemplo la decisión de firmar, o no, un petitorio en el que se reclama el derecho de ciudadanía para los inmigrantes. La argumentación de Agamben a la hora de explicar las razones de su rechazo a firmar la solicitud muestran a las claras que su decisión se desprende necesariamente de sus presupuestos filosófico-políticos. El punto que hemos querido resaltar sobre todo es que, en sus efectos concretos, la decisión de Agamben coincide con la de un hipotético fascista, pongamos por caso un partidario de la Liga Nord.

Para evitar estas consecuencias problemáticas, hemos propuesto distinguir dos dimensiones de lo político: una trascendental y una empírica. La primera haría referencia a las condiciones de posibilidad, y de allí el sentido kantiano de la terminología, de la política empírica. En esta dimensión se ubicarían, creemos, los planteos políticos de Agamben, en particular la noción de «desactivación», así como la tesis de Benjamin acerca de la naturaleza intrínsecamente violenta del aparato legal. Ambas nociones son trascendentales porque van a la raíz última de los dispositivos políticos: en el caso de Agamben, a la violencia inherente al funcionamiento antagónico de la máquina gubernamental, y en el caso de Benjamin a la violencia inherente al aparato jurídico. Esto significa que, más allá de sus contenidos empíricos, la estructura formal de ambas máquinas supone, necesariamente, a priori, un cierto uso de la violencia. No obstante, el objetivo de esta distinción interna a lo político tiene que ver con la necesidad de advertir que, si se realiza un pasaje directo de lo trascendental a lo empírico sin tomar ciertas cautelas o reparos, muchas veces se puede terminar adoptando una posición cercana al fascismo. En este sentido, tanto Agamben como el hipotético partidario de la Liga Nord coinciden en su decisión de no firmar el petitorio. Una manera de evitar este riesgo, estamos convencidos, es atender a la distinción propuesta 
con anterioridad. Los presupuestos trascendentales, en muchos casos, no son directamente aplicables a una política empírica. Es preciso considerar, por eso mismo, las complejidades de la dimensión empírica de lo político. De no hacerlo, se habrá tal vez conseguido una coherencia lógica o filosófica, pero se estará muy cerca de correr ese riesgo señalado paradójicamente por Benjamin y retomado, también paradójicamente, por Agamben. En suma, si no se tiene en cuenta esta distinción señalada, y sobre todo el pasaje de una dimensión a otra, bien podríamos hacer nuestras las palabras de Benjamin y dirigirlas ahora contra él mismo y contra el propio Agamben: ¡vous travaillez pour le fascisme!

\section{REFERENCIAS BIBLIOGRÁFICAS}

AGAMBEN, G. 1982: Il linguaggio e la morte. Torino: Einaudi.

AGAMBEN, G. 1990: La comunità che viene. Torino: Einaudi.

AGAMBEN, G. 1995: Homo sacer I. Il potere sovrano e la nuda vita. Torino: Einaudi. AGAMBEN, G. 1996: «Bataille et le paradoxe de la souveraineté», Liberté, 38(3), pp. 87-95.

AGAMBEN, G. 1996: Mezzi senza fine. Note sulla política. Torino: Bollati Boringhieri.

AGAMBEN, G. 2000: Il tempo che resta. Un commento alla Lettera ai Romani. Torino: Bollati Boringhieri.

AGAMBEN, G. 2002: L'aperto. L'uomo e l'animale. Torino: Bollati Boringhieri.

AGAMBEN, G. 2005: Estado de excepción. Homo sacer II, 1. Buenos Aires: Adriana Hidalgo.

AGAMBEN, G. 2007: Il Regno e la Gloria. Per una genealogia teologica dell'economia e del governo. Vicenza: Neri Pozza.

AGAMBEN, G. 2014: L'uso dei corpi. Vicenza: Neri Pozza.

AGAMBEN, G. 2017: Karman. Breve trattato sull'azione, la colpa e il gesto. Torino: Bollati Boringhieri.

BENJAMIN, W. «Zur Kritik der Gewalt», en BENJAMIN, W. Gesammelte Schriften, vol. II.1. Frankfurt am Main: Suhrkamp, 1999, pp. 179-204.

BLANCHOT, M. 1983: La communauté inavouable. Paris: Les Éditions de Minuit.

BLUMENTHAL-BARBY, M. 2009: «Pernicious Bastardizations: Benjamin's Ethics of Pure Violence», MLN, Volume 124, Number 3, April (German Issue), pp. 728-751.

CALARCO, M. 2008: Zoographies. The Question of the Animal from Heidegger to Derrida. New York: Columbia University Press.

DE LA DURANTAYE, L. 2009: Giorgio Agamben. A Critical Introduction. California: Stanford University Press. 
DERRIDA, J. 1967: L'écriture et la différence. París: Éditions du Seuil.

DERRIDA, J. 1994: Force de loi. Le 'fondement mystique de l'autorité'. Paris: Galilée.

DIDI-HUBERMAN, G. 2012: Supervivencia de las luciérnagas. Trad. Juan Calatrava. Madrid: Abada Editores.

ESPOSITO, R. 2006: Communitas. Origine e destino della comunità. Torino: Einaudi.

FENVES, P. 2010: The Messianic Reduction. Walter Benjamin and the Shape of Time. Stanford - California: Stanford University Press.

FOUCAULT, M. 1976: Histoire de la sexualité I. La volonté de savoir. Paris: Gallimard.

HAMACHER, W. 2013: Lingua amissa. Trad. Laura S. Carugati y Marcelo G. Burello. Buenos Aires: Miño y Dávila Editores.

JAMES, W. 1922: Pragmatism: A New Name for Some Old Ways of Thinking. London: Longmans, Green and Co.

KAMBAS, Ch. 1984: «Walter Benjamin lecteur des Réflexions sur la violence», Cahiers Georges Sorel, N², pp. 71-89.

KELLOGG, C. 2011: «Walter Benjamin and the Ethics of Violence», Law, Culture and the Humanities, 9(1), pp. 71-90.

LACLAU, E. 2008: «¿Vida nuda o indeterminación social?», en: LACLAU, E. Debates y combates. Por un horizonte de la politica. Trad. Leonel Livchitz. Buenos Aires: Fondo de Cultura Económica, pp. 107-123.

MARTEL, J. R. 2012: Divine Violence. Walter Benjamin and the Eschatology of Sovereignty. New York: Routledge.

MILLS, C. 2008: The Philosophy of Agamben. Ithaca. McGill-Queen's University Press.

MORAN, B. y SALZANI, C. (eds.) 2015: Towards the Critique of Violence. Walter Benjamin and Giorgio Agamben. New York: Bloomsbury Publishing.

MÜLLER, J.-W. 2003: «Myth, law and order: Schmitt and Benjamin read reflections on violence», History of European Ideas, 29, pp. 459-473.

NANCY, J.-L. 2004: La communauté désoeuvrée. Paris: Christian Bourgois Editeur.

PROCYSHYN, A. 2014: «Manifest Reason: Walter Benjamin on Violence and Collective Agency», Constellations, Volume 21, No 3, pp. 390-400.

PROZOROV, S. 2014: Agamben and Politics. A Critical Introduction. Edinburgh: Edinburgh University Press.

RINESI, E. 2015: Filosofía (y) Política de la Universidad. Buenos Aires: Ediciones UNGS.

SINNERBRINK, R. 2006: «Deconstructive Justice and the 'Critique of Violence': On Derrida and Benjamin». Social Semiotics, 16:3, pp. 485-497.

STEINER, U. 2010: Walter Benjamin. An Introduction to His Work and Thought. Trad. Michael Winkler. Chicago - London: The University Chricago Press. 
WATKIN, W. 2014: Agamben and Indifference. A Critical Overview. London - New York: Rowman \& Littlefield International, Ltd.

Germán Osvaldo Prósperi es Profesor Adjunto en la Universidad Nacional de La Plata, Argentina.

Líneas de Investigación:

El problema del sujeto en la filosofía contemporánea

\section{Publicaciones recientes:}

2018: "Quiasmo e imaginación en el 'último"Merleau-Ponty'». Diánoia. Revista de Filosofía, volumen LXIII, número 80 (Mayo), pp. 71-95. [Disponible en: http:// dianoia.filosoficas.unam.mx/files/2015/2755/1368/DIAN80_Prosperi.pdf].

2018: «La noción de 'esquema' en el pensamiento de Michel Foucault. Hacia una ontología de la imaginación». Ágora. Papeles de Filosofía, Vol. 37, nº 2, pp. $215-$ 235. [Disponible en: http://www.usc.es/revistas/index.php/agora/issue/view/375].

Correo electrónico: gerprosperi@hotmail.com 
